\title{
Improved treatment of Asthma by using natural sources of antioxidants
}

\author{
Nguyen Van Toan ${ }^{1,2^{*}}$ and Tran Thi Hanh ${ }^{3}$
}

A retraction article was published for this article. It is available from the following link; http://Ww springerplus.com/content/3/1/558

\begin{abstract}
A combined composition of the extracted powders from Hippocampus kuda and Rh oma Ho alomenae together

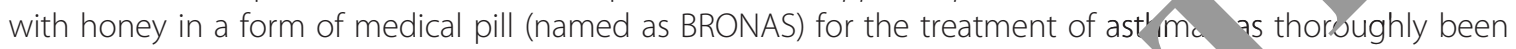
investigated under this study. BRONAS has shown its high anti-inflammatory effects ana rgng inhibition upon the pathogenesis of asthma. In comparison with other treatments without usin BR NAS, the restoration of patients' health was improved by a factor of $2-3$.

Clinical Trials with ACTR Number: ACTRN12612000766819

Keywords: Asthma, Bronchial asthma, Natural antioxidants, Pulmonary tury
\end{abstract}

\section{Introduction}

Asthma is a chronic disease characterized by inflammation of the airways (Buse and Lemanske 2001), a compley disorder characterized by variable and recurring $\operatorname{syn}_{\mathbf{n}} \mathrm{m}$ airflow obstruction, bronchial hyperresponsiy ness, $d$ an underlying inflammation. The interactior $/$ hese fea tures determines the clinical manifestations anc verity of asthma, and it has been reported as disease of ir.creasing prevalence (Expert Panel Report Guidelines for the diagnosis and management of asthm. VIH Publication No. 07-4051. 2007).

The pathogenesis of asthma is uniny in but imbalances between oxidants and intant are believed to play a fundamental role. $\mathrm{C}, \mathrm{ke}$ mponent of the oxidantantioxidant hypot 1 esis ce ors on the huge burden of oxidants derived $n$ inflam, atory cell infiltration into the lung. The eosinoph. in particular, is implicated as a major source of oxidative injary, including protein nitration (MacPherson 2011). Dysfunctional mitochondria in lung

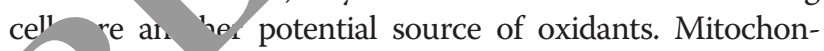
ial iury to airway epithelium occurs in murine models or argic asthma (Aguilera-Aguirre et al. 2009; Mabalirajan et al. j08). There is evidence to support its role in human asthma as well, including increased oxidative injury to

\footnotetext{
* Correspondence: nvtoan@hcmiu.edu.vn

${ }^{1}$ School of Biotechnology, International University, Ho Chi Minh City, Vietnam ${ }^{2}$ Faculty of Applied sciences, University of the West of England, Bristol, UK Full list of author information is available at the end of the article
}

mı hondrial epithelial cell superoxide dismutase (SOD) 'Com air et al. 2005), enhanced mitochondrial proliferation . $r$ onchial smooth muscle (Trian et al. 2007), and mutations in mitochondrial DNA (Reddy 2011). Overall, this oxidative burden, generated by both inflammatory and lung cells, can overwhelm antioxidant defense to cause oxidant stress during asthma. Thisk stress can alter or inactivate the function of essential proteins, lipids and nucleic acids culminating in severe cell injury, dysfunction and death.

Among many unknown and complicated mechanisms, involvement of airways inflammation with an oxidant/antioxidant imbalance such as reactive oxygen species (ROS) can lead to lung injury as a result of direct oxidative damage to epithelial cells and cells shedding. As inflammation is often associated with an increased generation of reactive oxygen species (ROS), it is rational to surmise that an oxidant stress could be mechanistically important in asthma. ROS have been shown to be associated with the pathogenesis of asthma by inducing bronchial hyperreactivity as well as directly stimulating histamine release from mast cells and mucus secretion from airway epithelial cells (Ryszard 2000).

The great external surface area $(1-2) \mathrm{m}^{2}$ of the human airway epithelium plus its direct contact with the environment, makes the respiratory tract a major target for oxidative injury from inhaled oxidants such as cigarette smoke, ozone, hyperoxia, nitrogen and sulphur oxides and other airborne pollutants. It has been well recognized that biological systems are capable of forming highly reactive 
moieties, both free radicals and non-radicals named reactive oxygen species (ROS) and reactive nitrogen species (RNS). Free radicals can especially be generated in a wide variety of chemical and biological systems, including the formation of plastics, the ageing of paints, the combustion of fuels and in the human body. In living organisms, the levels of free radicals and other 'reactive species' are controlled by a complex web of antioxidant defences, which minimize (but do not completely prevent) oxidative damage to biomolecules (Roberfroid and Calderon 1995; Gaston et al. 1994; Halliwell (2005).

These biologically active species serve in cell signaling as messenger molecules of the autocrine or paracrine system (Saran and Bors 1989; Suzuki et al. 1997 ) and also in host defense, (biocidal effects against microbial and tumor cells) (Babior 1978) but their excessive production may result in tissue injury and inflammation (Halliwell et al. 1992; Gutteridge and Halliwell 1994). Reportedly, any excessive production of oxidants is kept to a minimum by a well coordinated and efficient endogenous antioxidant defense mechanism. It has been proposed that a deficit in the precise balance between exposure to oxidants and endogenous antioxidants results in oxidative stress which appears to be involved in the pathogenesis of a growing number of diseases, including lung pathologies such a respiratory distress syndrome, asthma, idiopathic an 2 tr genic pulmonary fibrosis, cystic fibrosis, HIV assoch d lung disease, lung cancer and other pulmo diseast and conditions (Clement and Housset 1995; Barn 1995) . As excessive ROS levels damage lipid, proteins al, a nucleic acids through oxidation and thu are associated with various diseases, such as atherosclerosi generative disorders, and cancer regular supplement of antioxidants can assist the endogen wefense systems to counterbalance the han 1 eff cts of excessive ROS (Balsano and Alisi 20r Kay and Geetha 2006).

There has recer.ty be a remarkable increment in scientific articles a ing with oxidative stress (Urguiaga and Leighton 200u). ( vequently, knowledge about reactive oxygen and nitroger species metabolism; definition of markers ro xichtive damage; evidence linking chronic dis os a ox dative stress; identification of flavonoids nd o her dieary polyphenol antioxidants present in plant fo as bioactive molecules; and data supporting the idea at health benefits associated with fruits, vegetables in the diet are probably linked to the polyphenol antioxidants they contain. In addition, more than 8,000 polyphenolic compounds have been identified in various plant species and reported to possess many useful properties including antiallergic, antiinflammatory, antimicrobial, antiviral, antioxidant, oestrogenic, enzyme inhibition, vascular and cytotoxic anti- tumor activity (Pandey and Rizvi 2009; Asha et al. 2012).
According to Ji-Xiao Zhu et al., among many other contained phenolic compounds plants, Rhizoma Homalomenae has been shown to be positive linear correlations between total phenolic content and antioxidant activity of the extracts in the DPPH $(\mathrm{R}=0.9817)$, ABTS $(\mathrm{R}=0.9873)$, b-carotene/linoleic acid $(\mathrm{R}=0.8347)$ and reducing power $(\mathrm{R}=0.9876)$ tests, respectively.

Another source of natural antioxidants is natu " $\mathrm{y} \mathrm{oc}_{\mathrm{C}}$ curring from traditional Chinese medicines sources, been identified as free radical or active ren sca engers (Duh 1998; Pan et al. 2007). Natural arrioxic ts an protect the human body from free rad als and ret, $\mathrm{d}$ the progress of many chronic diseases well as retard lipid oxidative rancidity in foods o nean materials (Kang et al. 2008). Among the rany mo ioned sources of naturally occurring antioxia Seahorse (Hippocampus kuda Bleeker) has been well $k_{n} \quad n /$ for its special medicinal composition. Ac cor $\mathrm{g}$ to Zh.ong-Ji Qian et al., the methanol extracts or $s$ itained high amount of phenolic compounds and $t$ extracts exhibited good antioxidant activity by as DPPH $\mathrm{rid}$ dicar, hydroxyl radicals, superoxide anion radicals, alkyl ra dicals, and reducing the ferric to ferrous ion in ain. nt antioxidant systems.

In search for treatment that might stop the recurrent cls s of breathlessness and wheezing to make it more surceptible to at least, providing relief for asthmatic pacients, and if possible to treat the asthmatic disease, a method has emerged that seems to be extremely useful for application of natural sources of antioxidants for treatment of asthma. The method was using finely extracted powders from the seahorse (Hippocampus kuda) and Rhizoma Homalomenae (with a ratio of $1: 1 \mathrm{w} / \mathrm{w}$ ) in honey to form into pill of $500 \mathrm{mg}$. All the hand-rolled pills were dried in an oven at $55^{\circ} \mathrm{C}$ until the moisture content of the pill was consistent.

In this paper, successful application of extracted powders from the seahorse (Hippocampus kuda) and Rhizoma Homalomenae together with honey in the form of medical pill for treatment of asthma is reported.

\section{Materials and methods}

Preparation of extracts from seahorse (Hippocampus kuda)

The antioxidant extracts were prepared by adopting the method of Zhong-Ji Qian to check the total phenolic content and determine the total antioxidant activity.

\section{Preparation of extracts from Rhizoma Homalomenae}

The plant materials of Rhizoma Homalomenae used in this study was donated by DUC- HUNG- a traditional medicine shop in Nhatrang City- a central part of Vietnam. The dried materials were ground to the fine powder and passed through a 20-mesh sieve for the preparation of extracts. 


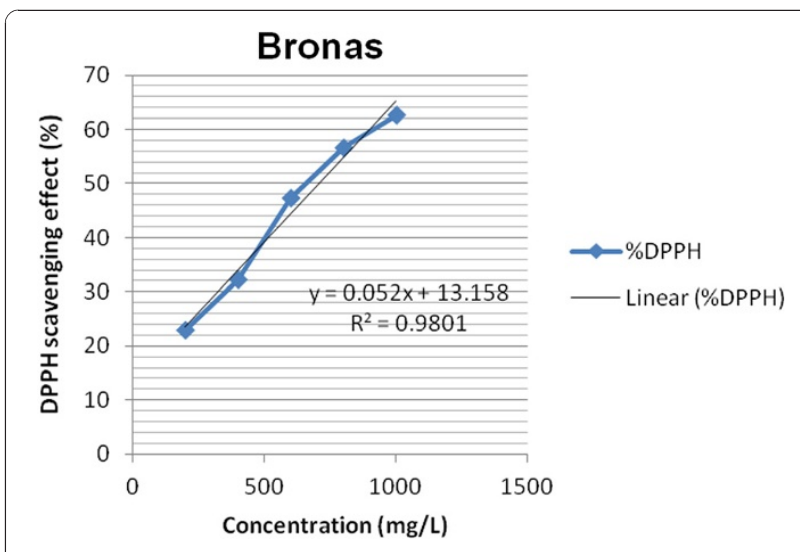

Figure 1 The DPPH free radical scavenging of the BRONAS sample.

The sieved powder was subjected to water distillation for 5 hrs by adopting the method of Zeng et al. 2011.

\section{Preparation of medicinal pills}

In this study, a dosage of 500mg pill was prepared and named as BRONAS, and described as below:

BRONAS was prepared from $200 \mathrm{mg}$ of dried extract powder of Hippocampus kuda", $200 \mathrm{mg}$ of dried ext act powder of Rhizoma Homalomenae and 130 o f honey $^{* * * *}$, and then hand - rolled into pills raro d $500 \mathrm{mg}$, each.

\section{Notes}

"The moisture content of the ' ' exied ex powder of Hippocampus kuda was 3\%.

**The moisture content the di ed extract powder of Rhizoma Homalom aee vas 3\%.

***The moisture ante. of tru used honey was $17 \%$.

All the han - ro 4 pills were dried in an oven at $55^{\circ} \mathrm{C}$ for 34 to 46 hours. sisture content of the pill was determin by the tandard AOAC method (AOAC 2000)
Determination of total antioxidant activity of BRONAS

The antioxidant activity of BRONAS was determined right after drying the pills to the consistent moisture content. The antioxidant potential of BRONAS was determined on scavenging activity of the DPPH Free- Radical by adopting the method described by Sadhu et al. (2003).

The maximum absorption $(\lambda \max )$ of a stab e $\mathrm{PPPH}$ in methanol is $520 \mathrm{~nm}$ and the results are exp ea as $\mathrm{IC}_{50}$ values. The percent inhibition, radical scavt $\mathrm{gg}$ capacity was calculated using the follow. equati n.

$$
D P P H \text { scavenged }(\%)=\frac{(A \text { con }}{A c \text { rol }-A \text { sampe })}
$$

Where: A control = $\mathrm{A}$ sorban of $\mathrm{DPPH}$ alone.

A sample = Absorban of DPP, $A$ along with different concentrations of extractea mple.

$\mathrm{IC}_{50}$ was calo ala I from the slope obtained by plotting a graph or $n$ ion versus \% inhibition.

According to Ml neux P (Molyneux 2004) DPPH is the molecule 1-dipb.enyl-2-picrylhydrazyl $(\alpha, \alpha$-diphenyl $\beta$ picrylhydrazy , aracterized as a stable free radical by virtue of the delocalization of the spare electron over the mu ule as a whole, so that the molecules do not dimerize, as we ld be the case with most other free radicals. The adization also gives rise to the deep violet colour, characterized by an absorption band in ethanol solution cencered at about $520 \mathrm{~nm}$. When a solution of DPPH is mixed with that of a substance that can donate a hydrogen atom, then this gives rise to the reduced form. With the loss of this violet colour (although there would be expected to be a residual pale yellow colour from the picryl group still present). Representing the $\mathrm{DPPH}$ radical by $\mathrm{Z}^{*}$ and the donor molecule by $\mathrm{AH}$, the primary reaction is $\mathrm{Z}^{*}+\mathrm{AH}=$ $\mathrm{ZH}+\mathrm{A}^{*}$

Where:

- $\mathrm{ZH}$ is the reduced form

- $A^{*}$ is free radical produced in this first step.

The latter radical will then undergo further reactions which control the overall stoichiometry, that is, the

\begin{tabular}{|c|c|c|c|c|c|c|}
\hline & Blank & $200 \mathrm{mg} / \mathrm{L}$ & $400 \mathrm{mg} / \mathrm{L}$ & $600 \mathrm{mg} / \mathrm{L}$ & $800 \mathrm{mg} / \mathrm{L}$ & $1000 \mathrm{mg} / \mathrm{L}$ \\
\hline & 0.53 & 0.40 & 0.38 & 0.28 & 0.24 & 0.19 \\
\hline & 0.51 & 0.41 & 0.33 & 0.25 & 0.22 & 0.10 \\
\hline & 0.53 & 0.42 & 0.37 & 0.30 & 0.23 & 0.21 \\
\hline Mean & 0.52 & 0.41 & 0.36 & 0.28 & 0.23 & 0.20 \\
\hline SD & 0.01 & 0.01 & 0.02 & 0.03 & 0.01 & 0.01 \\
\hline CV (\%) & 2.10 & 1.72 & 6.30 & 9.54 & 5.51 & 4.30 \\
\hline DPPH (\%) & 0 & 22.91 & 32.21 & 47.32 & 56.62 & 62.70 \\
\hline
\end{tabular}


Table 2 The effects of BRONAS and PREDISONE on pulmonary functions test

\begin{tabular}{|c|c|c|c|c|c|c|c|c|}
\hline \multirow[t]{2}{*}{ Drug } & \multicolumn{2}{|c|}{ FVC \% } & \multicolumn{2}{|c|}{ FEV1 \% } & \multicolumn{2}{|c|}{ MMEFR \% } & \multicolumn{2}{|c|}{ PEFR } \\
\hline & Before & After & Before & After & Before & After & Before & After \\
\hline PREDISONE & $63.45 \pm 11.94$ & $65.55 \pm 12.50$ & $51.14 \pm 11.63$ & $* 54.78 \pm 12.20$ & $50.28 \pm 22.45$ & $51.72 \pm 11.60$ & $2.96 \pm 1.34$ & $3.57 \pm 2.32$ \\
\hline BRONAS & $61.38 \pm 15.60$ & ${ }^{*} 69.35 \pm 5.32$ & $55.39 \pm 15.63$ & ${ }^{*} 65.32 \pm 5.16$ & $53.28 \pm 22.45$ & $* 62.05 \pm 3.60$ & $3.26 \pm 1.54$ & $* 5.94 \pm 2.50$ \\
\hline
\end{tabular}

*Results were significant at $(p<0.05)$

number of molecules of DPPH reduced (decolorized) by one molecule of the reductant.

In this study, stock solutions of the BRONAS sample were used for preparing various concentrations of 200, 400, 600, 800 and 1000 (mg/L).

\section{Patients}

This study was performed at the Home Clinic, $345 \mathrm{D}_{5}$ Street, Binh Thanh District of Ho Chi Minh city, Vietnam between September 2011 to early April 2013.

Ninety two asthmatic patients (55\% males and $45 \%$ females) who come from different parts of Vietnam, were randomly selected and included in the study. Their age range was $12-65$ years. All Patients were desperately suffering from disease of asthma and all of them were many times hospitalized and measured value of $\mathrm{FEV}_{1} /$ FVC were from $50 \%$ to $60 \%$, of which the shortest disease history was 3 years and the longest was 11 year. it is worth noting here that most of the participat: $p$. tients experienced a set of clinical symptoms which sult in the sensation of difficulty breatb. such a Spasm of the bronchial muscles and shortness o reathing, cough, expectoration, and pronged exp,atory phase with wheezing. In addition, all of the participating patients were those, who had ever us high loses of inhaled corticosteroids and partic arly long acting inhaled

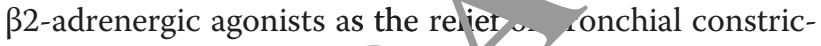
tion to reduce the asthr. epis des.

Pulmonary functio- test unc nerformed by Spirometry test, adopting the rinetho ff Faruk et al. 2010 for checking possible effects of the given medicines on the treat tients. By applying this, a total computa ed spit ometer (Discom-14 Autospiror, Chest Corporation kyo, Japan) that measures Forced Volume $C$ pacity $(F \bigvee, C)$, Forced Expiratory Volume in First Secon (FEV1) Peek Expiratory Flow Rate (PEFR), and in imain -expiratory Flow Rate (MMEFR) was exter sively $\mathrm{a}_{1}$ 'ied as it would provide predicted values.

The patients were then in tomly allocated to 2 groups of A and B. The $\mathrm{g}_{2}$ up A o: 40 (18 Males: 22 Females) patients was $g$. $n$ ISONE with a single dose of $10 \mathrm{mg} / \mathrm{kg}$ of boa weight, daily for each 21 days and stopped $\mathrm{t}$ lmonary function check. The group B (24 Male: $28 \mathrm{~F}$ er/ary, was given BRONAS with a single dose of $1200 \mathrm{mg} / \mathrm{kg}$ of body weight, daily for 21 days and Sto ad for pulmonary function check as well. The

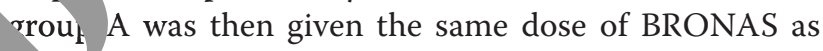
the group B for 21 days for further comparing the an 1-inflammatory effect of BRONAS with the antiinflammatory effect of PREDISONE.

\section{Data analysis}

All data are expressed as means \pm standard deviation representative of similar tests carried out in triplicate. Statistical differences were determined by student's $t$-test in which, $\mathrm{p}<0.05$ was considered as statistically significant.

\section{Ethics}

All participated patients gave their consent prior to participation in the study.

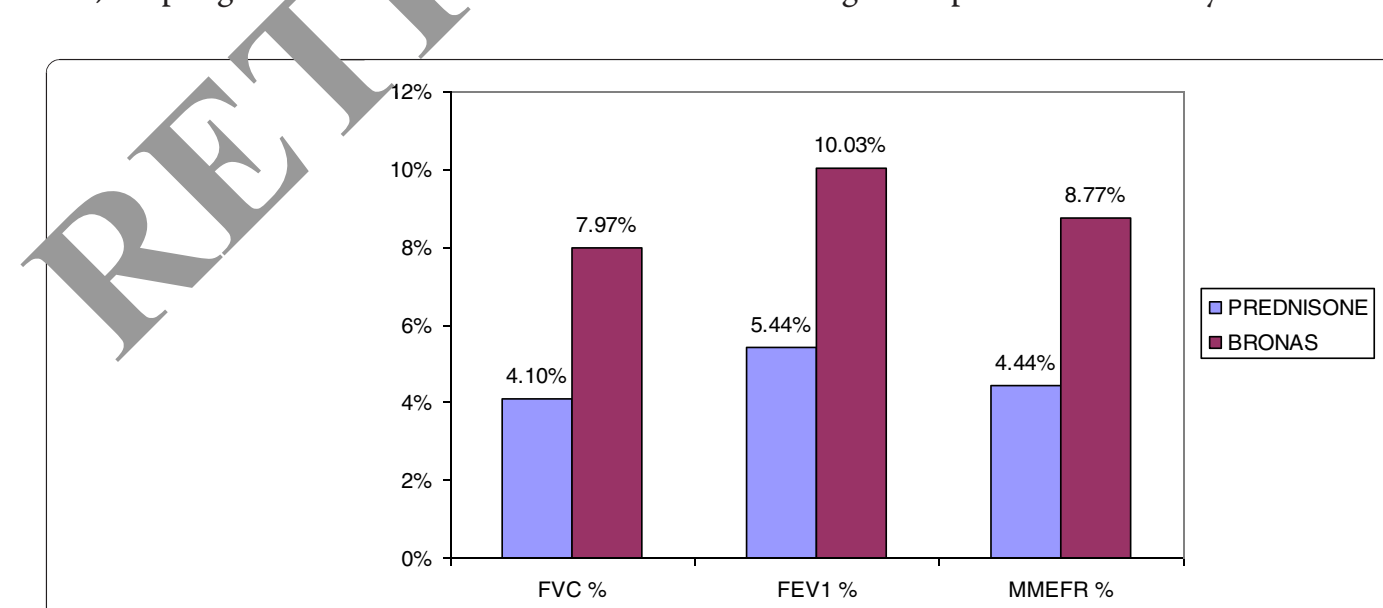

Figure 2 Percentage increment in FVC, FEV ${ }_{1}$, MMEFR after treatment with PREDNISONE and BRONAS. 
Table 3 The effects of BRONAS on pulmonary functions test in the post treatment of PREDISONE

\begin{tabular}{|c|c|c|c|c|c|c|c|c|}
\hline \multirow[t]{2}{*}{ Drug } & \multicolumn{2}{|c|}{ FVC \% } & \multicolumn{2}{|c|}{ FEV $_{1} \%$} & \multicolumn{2}{|c|}{ MMEFR \% } & \multicolumn{2}{|c|}{ PEFR } \\
\hline & Before & After & Before & After & Before & After & Before & After \\
\hline BRONAS & $65.63 \pm 12.44$ & *73.80 \pm 9.67 & $62.34 \pm 14.21$ & *71.95 \pm 10.18 & $52.34 \pm 19.16$ & $* 60.92 \pm 11.06$ & $3.15 \pm 1.75$ & $* 5.86 \pm 2.40$ \\
\hline
\end{tabular}

*Results were significant at $(p<0.05)$

\section{Results}

Data on total antioxidant activity of BRONAS were shown in the Table 1 and Figure 1. The values obtained were also shown that the DPPH scavenging effect in percentage of BRONAS were three times higher than those extracted from green tea using the same method of extraction (Yen and Chen 1995)

The Forced Volume Capacity (FVC), Forced Expiratory Volume in First Second (FEV1), Peek Expiratory Flow Rate (PEFR), and Maximal Mid-expiratory Flow Rate (MMEFR) were extensively applied for determining the response to the therapy and monitoring the rate of progression. The results have been summarized and shown in the Table 2 and Figure 2.

The ratio of $\mathrm{FEV}_{1}$ to $\mathrm{FVC}(\mathrm{v} / \mathrm{v})$ after treatment was calculated using the formula:

$$
\frac{F E V_{1 \text { after treatment }}}{F V C_{\text {after treatment }}}=\text { Value in percentage }
$$

The ratio of $\mathrm{FEV}_{1}$ to $\mathrm{FVC}(\mathrm{v} / \mathrm{v})$ after 21 davo of $\mathrm{t}_{1}$ ment with PREDNISONE was $84.50 \%$.

The ratio of $\mathrm{FEV}_{1}$ to $\mathrm{FVC}(\mathrm{v} / \mathrm{v})$ after treatn. BRONAS was $94 \%$.

As the ratio of $\mathrm{FEV}_{1}$ to $\mathrm{FVC}(\mathrm{v} /)$ after $\mathrm{P1}$ days of treatment with PREDNISONE was i. rover but lower (84.50\%) than the one obtaine ${ }^{\text {c }}$ om the treatment with BRONAS (94\%) in the same perioc/ eatment process, the asthmatic patients Groul A was then continuously given BRONA vith singre dose of $1200 \mathrm{mg} / \mathrm{kg}$ daily for another $\mathbf{2 1}$ a of treatment. The collected data in this sta f treatn ht has been summarized and shown in the rable and Figure 3.

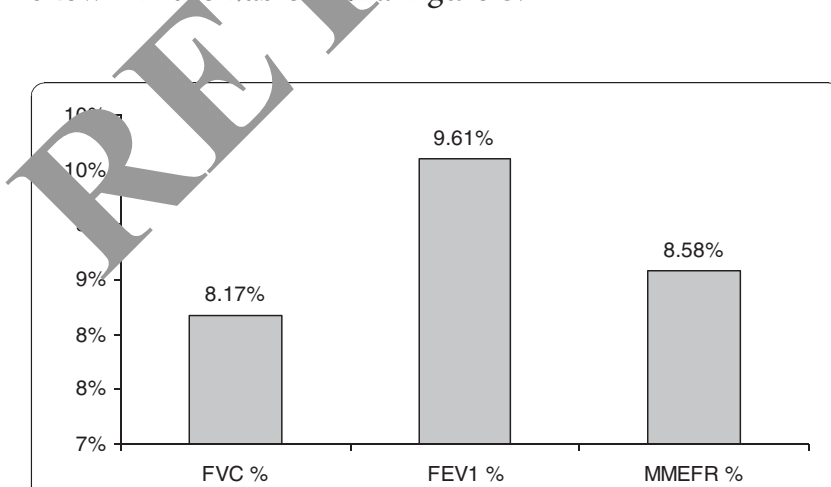

Figure 3 Percentage increment in FVC, FEV 1 , MMEFR in the post treatment of PREDISONE with BRONAS.
After all the all ninety two patients having ad treatment with BRONAS as given dose in the ating process mentioned above, sets of pulmonary fun $1 \mathrm{~s}$ test were conducted and found that tif $83^{\text {th }}$ day of treatment, all the asthmatic patientc wore 0 / almost fully recovered. The result of pu monary fui,ctions test has been summarized and shown Figure 4 .

This statement has been a oliu. by the fact that no clinical symptoms the ase asthmatic disease such as Spasm of the on hial miscles and shortness of breathing, cough, expector on, and prolonged expiratory phase with wh zing weie seen again.

\section{Discussion}

From the $\quad V_{2}$, it could be reasoned that there was no significant incre, se in FVC\%, MMEFR\% and PEFR but only $\mathrm{FEV}_{1} \%$ by using single PREDNISONE in group $\mathrm{A}$. In lition, the ratio of $\mathrm{FEV}_{1}$ to $\mathrm{FVC}(\mathrm{v} / \mathrm{v})$ after 21 days of tre ment was $84.50 \%$.

$\checkmark$ group B, a significant improvement in Pulmonary Function Tests associated with improvement in patients' clinical conditions was observed. After taking the BRONAS for the same period of treatment, the ratio of $\mathrm{FEV}_{1}$ to FVC (v/v) was pretty high (94\%).

Data collected from the oral administration of BRONAS of patients in group $\mathrm{A}$, of which shown in Table 3 and Figure 4 would again support and explain the beneficial effect of taking BRONAS in reducing the incidence of

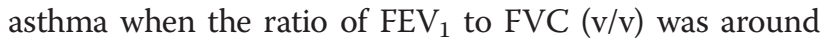
97.50\%.

$\mathrm{FEV}_{1}$ has been found to be a better physiologic index than PEFR in the measurement of airflow obstruction (Christophe et al. 1998). So in this study, the values of PEFR were used as a reference to possibly support and/or explain

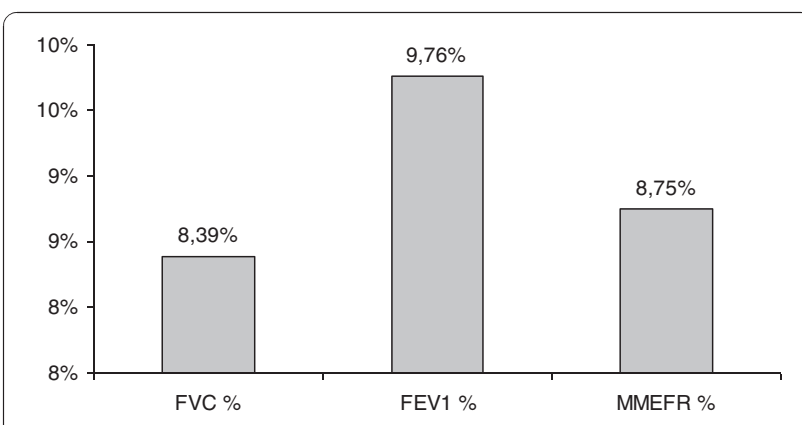

Figure 4 Percentage increment in FVC, $\mathrm{FEV}_{1}$, MMEFR in the $83^{\text {rd }}$ treatment with BRONAS. 
the beneficial effect of orally administering the prescribed and prepared medical tablet/ pill in reducing, even treating the incidence of asthma.

The strong antioxidant properties of the BRONAS may be attributed to the presence of the combined bioactive antioxidant compounds from the extract of Hippocampus kuda and those of Rhizoma Homalomenae. Based on the report of Zhong et al. (2008), the extracted antioxidants from Hippocampus kuda contained effective reducing power, DPPH radical scavenging, hydroxyl radical scavenging, superoxide radical scavenging, alkyl radical scavenging and inhibitory intracellular ROS. Zheng and Wang (2001) reported that the strong antioxidant properties of the Rhizoma Homalomenae extracts may be due to the presence of phenolics compounds such as protocatechuic acid, vanillic acid, syringic acid, caffeic acid, p-coumaric acid, ferulic acid and apigenin. Phenolic acids are the main phenols consumed by humans (Ghasemzadeh and Ghasemzadeh 2011). The six phenolics mentioned above are all prominent and naturally occurring, and all of them individually possess potent antioxidant activity (3 Joskova et al. 2013; Gao et al. 2012). The honey was intentionally used with the dried extract powder of Rhizoma Homalomenae and that of Hippocampus kuda since it has been scientifically considered as an antimicrobial agent and chelating in traditional medi-ne. In addition, there is a great variety of minor nents, including phenolic acids and flavonoid (Na. et al. 1999; Joskova et al. 2013), the enzyme \& cose ox, dase, ascorbic acid, carotenoids, organic acia amino acids, proteins and $\alpha$-tocopherol (Kes c et al. 200\%, .

By and large, the results obtain f from this study showed that BRONAS can protect o lar omponents from many types of oxidative ?s by Doth free radical scavenging mechanism and stabil izl so cell membranes and this may explain t/. nprovement that occurred in both dynamic perfor, nce f the lung in moving air and the elastic recoil/urce the lung, especially when the ratio of $\mathrm{FEV}_{1}$ to $\mathrm{C}$ reach, 4 at least $94 \%$.

\section{Conclusion}

The stu no strates that the combined antioxidants from extr. od powders of Hippocampus kuda and hizo la Hov lalomenae together with honey in a form of $\mathrm{n}$. Car $\mathrm{Cu}$ (BRONAS) can help improve the treatment of asth BRONAS can be used to replace synthetic antioxidants, which are being restricted due to their side effects such as carcinogenicity. In addition, BRONAS can be prepared at a lower cost and in a more friendly way.

\section{Ethical approval}

The ACTRN12612000766819 was the Retrospectively registered and approved by Australian New Zealand Clinical Registry.

\section{Competing interest}

The authors declare that they have no competing interest.

\section{Authors' contribution}

NVT has been responsible for the all technical matters, scientific issues/values and the manuscript preparation. TTH has been responsible for patients recruitment and proof reading. Both authors read and approved the final manuscript.

\section{Acknowledgements}

The authors would like to express their sincere thanks to the Nguyer research funds. They would like to extend their thanks to the Buddhist Thich Giac Lam from Dat Nhau ward, Bu Dang District, B: Phuoc Provinc, Vietnam for the supply of raw materials of Rhizoma Homan snae.

\section{Author details}

${ }^{1}$ School of Biotechnology, International Unive ty, Ho Chi Min'h City, Vietnam. ${ }^{2}$ Faculty of Applied sciences, V'ivers the West of England, Bristol, UK. ${ }^{3}$ Home Clinic, 345 D5 Street, Thar. strict, Ho Chi Minh City, Vietnam.

Received: 25 May 2013 Acc ptec June 2013

Published: 26 June 2013

\section{References}

AOAC (2000) Determina of morsture content. Association of Official Analytical Chemist Washington

Aguilera-Agui -al (200\%) Mitochondrial dysfunction increases allergic airway inflammation. im inol 183(8):5379-5387

Asha KK, Suseelo MM, Lakshmaman PT (2012) Flavonoids and phenolic compounds in two mang ve species and their antioxidant property. Indian J Geo Mar 1(3):259-264

Babion (1978) Oxygen-dependent microbial killing by phagocytes. N Engl J 298:658-9

C, Alisi A (2009) Antioxidant effects of natural bioactive compounds. Curr Pharm Des 15:3063-3073

Jarnes PJ (1995) Nitric oxide and airway disease. Ann Med 27:389-93

Buse WW, Lemanske RF Jr (2001) Asthma. N Engl J Med 344:350-362

Christophe L, Luca P, Carole T (1998) Comparison of Serial Monitoring of Peak Expiratory Flow and FEV1 in the Diagnosis of Occupational Asthma. Am J Respir Crit Care Med 158(3):827-832

Clement A, Housset B (1996) Role of free radicals in airway injury. In: Chretien J, Dusser D (eds) Environmental impact on the airways. Dekker, New York, pp 355-79

Comhair SA, Xu W, Ghosh S et al (2005) Superoxide dismutase inactivation in pathophysiology of asthmatic airway remodeling and reactivity. Am J Pathol 166(3):663-674

Duh PD (1998) Antioxidant activity of burdock (Arctium lappa Linné): Its scavenging effect on free-radical and active oxygen. J Am Oil Chem Soc 5:455-461

Faruk H, Jawad A, Hayder G et al (2010) Usefulness of antioxidant drugs in Bronchial asthma. Pak J Physiol 6(2):18-21

Gao F, Wei D, Bian T et al (2012) Genistein attenuated allergic airway inflammation by modulating the transcription factors T-bet, GATA-3 and STAT-6 in a murine model of asthma. Pharmacology 89(3-4):229-36

Gaston B, Drazen JM, Loscalzo J et al (1994) The biology of nitrogen oxides in the airways. Am J Respir Crit Care Med 149:538-51

Ghasemzadeh A, Ghasemzadeh N (2011) Flavonoids and phenolic acids: Role and biochemical activity in plants and human. J Med Plants Res 5(31):6697-6703, 23

Gutteridge JMC, Halliwell B (1994) Antioxidants in nutrition, health and disease. Oxford University Press, Oxford

Halliwell B, Gutteridge JMC, Cross CE (1992) Free radicals, antioxidants and human disease: where are we now? J Lab Clin Med 119:598-620

Halliwell B (2005) Free radicals and other reactive species in disease. In: eLS. John Wiley, Chichester, http://www.els.net [doi: 10.1038/npg.els.0003913]

Joskova M, Sadlonova V, Nosalova G et al (2013) Polyphenols and their components in experimental allergic asthma. Adv Exp Med Biol 756:91-8

Kang KS, Kim ID, Kwon RH et al (2008) Undaria pinnatifida fucoidan extract protects against CCl4-induced oxidative stress. Biotechnol. Bioprocess Eng 13:168-173

Kaur IP, Geetha T (2006) Screening methods for antioxidants-a review. Mini Rev Med Chem 6(3):305-312 
Kesic A, Mazolovic M, Crnkic A et al (2009) The Influence of L-Ascorbic Acid Content on Total Antioxidant Activity of Bee-Honey. Eur J Sci Res 32(1):95-101

Mabalirajan U, Dinda AK, Kumar S et al (2008) Mitochondrial structural changes and dysfunction are associated with experimental allergic asthma. J Immunol 181(5):3540-3548

MacPherson JC, Comhair SA, Erzurum SC et al (2011) Eosinophils are a major source of nitric oxide-derived oxidants in severe asthma: characterization of pathways available to eosinophils for generating reactive nitrogen species. J Immunol 166(9):5763-5772

Molyneux P (2004) The use of the stable free radical diphenylpicrylhydrazyl (DPPH) for estimating an antioxidant activity. Songklanakarin J Sci Technol 26 (2):211-219

Natella F, Nardini M, Felice MD, Scaccini C (1999) Benzoic and cinnamic acid derivatives as antioxidants: structure-activity relation. J Agric Food Chem 47:1453-1459

Pan Y, Zhu J, Wang H et al (2007) Antioxidant activity of ethanolic extract of Cortex fraxini and use in peanut oil. Food Chem 103:913-918

Pandey KB, Rizvi SI (2009) Plant polyphenols as dietary antioxidants in human health and disease. Oxid Med Cell Longev 2(5):270-278

Reddy PH (2011) Mitochondrial Dysfunction and Oxidative Stress in Asthma: Implications for Mitochondria-Targeted Antioxidant Therapeutics. Pharmaceuticals (Basel) 4(3):429-456

Roberfroid M, Calderon PB (1995) Biologically relevant radicals. In: Roberfroid M, Calderon PB (eds) Free radicals and oxidation phenomena in biological systems. Marcel Dekker Inc, New York, pp 33-90

Ryszard D (2000) Oxidant stress in asthma. Thorax 55(Suppl 2):S51-S53

Sadhu SK et al (2003) Separation of Leucas aspera, a medicinal plant of Bangladesh, guided by prostaglandin inhibitory and antioxidant activities. Chem Pharm Bull 51:595-98

Saran M, Bors M (1989) Oxygen radicals acting as chemical messenger: a hypothesis. Free Rad Res Commun 7(3-6):213-20

Suzuki YJ, Forman HJ, Sevanian A (1997) Oxidants as stimulators of signal transduction. Free Rad Biol Med 22:269-85

Trian T, Benard G, Begueret $\mathrm{H}$ et al (2007) Bronchial smooth muscle remodel involves calcium-dependent enhanced mitochondrial biogenesis in ? hmm. J Exp Med 204(13):3173-3181

Urguiaga I, Leighton F (2000) Plant polyphenol antioxidants and oy arative s Biol Res 33:55-64

Yen GC, Chen HY (1995) Antioxidant Activity of Various Tea E tract. Relation to Their Antimut agenicity J. Agric. Food Chem 43:27-37)

Zeng LB et al (2011) Antioxidant activity and chemica' constituents of es,ential oil and extracts of Rhizoma Homalomenae. Food them 125:456-463

Zheng W, Wang SY (2001) Antioxidant activity and p olic compounds in selected herbs. J Agric Food Chem 49:5165-5170

Zhong JQ et al (2008) Free Radical and Reac axygen Species Scavenging Activities of the Extracts from Seahorse, A ppo kuda Bleeler. Biotechnol Bioprocess Eng 13:705-715
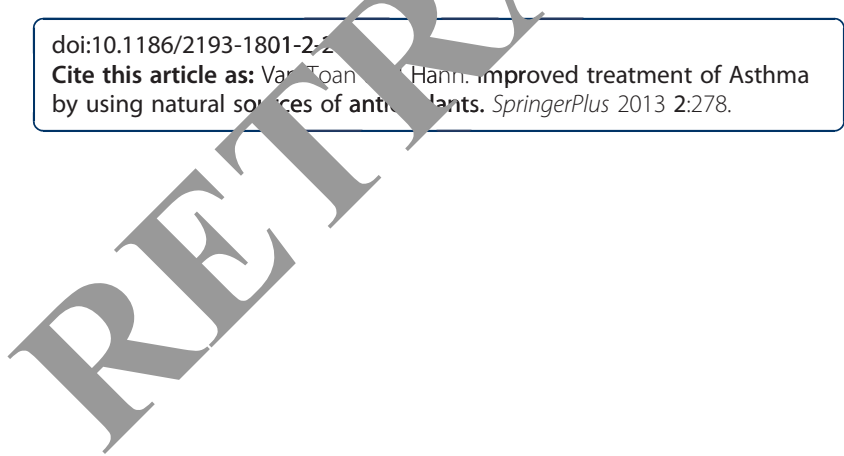

\section{Submit your manuscript to a SpringerOpen ${ }^{\circ}$ journal and benefit from:}

- Convenient online submission

Rigorous peer review

- Immediate publication on acceptance

- Open access: articles freely available online

- High visibility within the field

- Retaining the copyright to your article

Submit your next manuscript at $\gg$ springeropen.com 